\title{
Platinum nanocrystals supported by silica, alumina and ceria: metal- support interaction due to high-temperature reduction in hydrogen
}

\author{
S. Penner ${ }^{*}$, D. Wang ${ }^{2}$, D.S. Su${ }^{2}$, G. Rupprechter ${ }^{2}$, R. Podloucky ${ }^{3}$, R. Schlögl ${ }^{2}$, K. Hayek ${ }^{1}$
}

${ }^{1}$ Institut für Physikalische Chemie, Leopold-Franzens-Universität, Innrain 52a, A-6020 Innsbruck, Austria

${ }^{2}$ Department of Inorganic Chemistry, Fritz-Haber-Institute of the MPG, Faradayweg 4-6, 14195 Berlin, Germany

${ }^{3}$ Center for Computational Materials Science \& Universität Wien, Liechtensteinstr. 45, A-1090 Vienna, Austria

${ }^{*}$ Corresponding author: e-mail simon.penner@,uibk.ac.at, phone +43 512507 5066, fax +43 5125072925

Submitted 24 June 2002; accepted 10 October 2002

\begin{abstract}
Regular Pt nanoparticles, obtained by epitaxial deposition on $\mathrm{NaCl}$ surfaces, were supported by thin films of silica, alumina and ceria and subjected to hydrogen reduction at temperatures up to $1073 \mathrm{~K}$. The changes in morphology and composition were followed by (HR)TEM, electron diffraction and EELS, and the results were supported by theoretical calculations. The structural changes of the Pt particles upon reduction at 773 $\mathrm{K}$ and above are surprisingly similar despite the differing chemical properties of the three supports. Some platelet- and cube-like geometries exhibit double lattice periodicities in high resolution images and electron diffraction patterns. With increasing reduction larger aggregates of more complex appearance and structure are formed. Surface reconstruction under hydrogen and alloy formation are considered as responsible for this

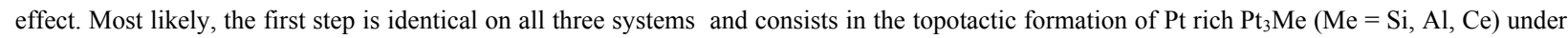
the influence of hydrogen, followed by transformation into diverging structures of lower Pt content and different crystallography. Density functional calculations were performed for deriving energies of formation of $\mathrm{PtMe}$ and $\mathrm{Pt}_{3} \mathrm{Me}$ compounds.
\end{abstract}

Keywords: Platinum, electron microscopy, surface reconstruction, alloy, catalysis

\section{Introduction}

In heterogeneous catalysis model systems are invaluable tools for resolving the mechanism of structure-sensitive reactions. Lately, noble metal nanocrystals grown epitaxially on $\mathrm{NaCl}$ and integrated into different supporting films have been successfully studied as model systems for supported catalysts $[1,2]$. Regular metal particles partly embedded in thin planar supports facilitate the characterisation by electron microscopy and provide a defined initial state for subsequent structural alterations due to oxidation and reduction. They are also well suited to study the influence of different supports on identical nanoparticles.

Noble metals in combination with a reducible oxide (e.g. ceria) are known to undergo metal-support interaction which may strongly influence the catalytic activity in various chemical reactions. This usually occurs under hightemperature treatment in hydrogen and is manifest either as a change of the structure and surface area of the oxide and/or the metal ("geometric effect") or as an "electronic" (chemical) interaction between the metal and the (partially) reduced oxide [3]. However, structural and chemical changes on (and of) non-reducible supports like alumina and silica upon reduction at $\geq 773 \mathrm{~K}$ have also been reported [4]. Since the described thin film model catalysts allow to investigate systems containing different supports but identical metal particles, the present work was dedicated to the structural and morphological changes of both non-SMSI and SMSI systems (Pt supported by alumina, silica and ceria) subjected to various activation procedures. Systematic series of reduction were performed in the temperature range between 673 and $1073 \mathrm{~K}$. The resulting changes were followed with electron 
microscopy and related techniques (TEM, HRTEM, TED and EELS) and interpreted by means of density functional calculations.

\section{Experimental}

Pt particles (mean size 10 to $15 \mathrm{~nm}$ ) were epitaxially grown on vacuum-cleaved (001) $\mathrm{NaCl}$ single crystal surfaces and on fresh deposited $\mathrm{NaCl}$ thin films. The metal was deposited at $673 \mathrm{~K}$ by electron beam evaporation at $10^{-6}$ mbar pressure (the nominal metal coverage of the $\mathrm{NaCl}$ surface was 2,5 - 3 $\mathrm{nm})$. The samples were then covered with a supporting film of amorphous silica or alumina or of crystalline ceria (15 to $25 \mathrm{~nm}$ thick), prepared by reactive deposition in $10^{-4} \mathrm{mbar}$ oxygen of $\mathrm{SiO}$, aluminium metal and cerium oxide, respectively. Subsequently, the $\mathrm{NaCl}$ was dissolved in water and the films were mounted on gold EM grids [1]. After oxidation $\left(\mathrm{O}_{2}, 673 \mathrm{~K}, 1 \mathrm{~h}\right)$ the samples were exposed to $\mathrm{H}_{2}$ between 673 and $1073 \mathrm{~K}$ for $1 \mathrm{~h}$, either in a flow system or in a circulating batch reactor. Their morphology and structure were examined by HRTEM and compared to the as-grown state. The images were taken with a Zeiss EM 10C, with a Philips CM FEG 200 and with a JEOL 4000 microscope. EELS measurements were performed at the Philips CM FEG 200 equipped with a Gatan energy filter.

\section{Results}

For a comparison of structural and morphological changes due to reduction the initial state has to be well defined. Fig. 1a shows a low-magnification image of as-deposited Pt particles supported by a silica film ( $25 \mathrm{~nm}$ thick). The high metal loading of the $\mathrm{NaCl}$ surface has resulted in large (mean diameter $12 \mathrm{~nm}$ ) and relatively closely spaced particles. Most exhibit square or rectangular shapes and are identified as (truncated) half octahedra by weak-beam dark field imaging (Fig. 1b) [1]. The SAED pattern (insert in Fig.1a) confirms their almost perfect orientation with respect to the original $\mathrm{NaCl}$ substrate. Most of the particles are in their [100] zone and no $\operatorname{Pt}(111)$ reflections are detected. The high-resolution image of octahedral particles (insert) shows Pt (200) lattice fringes $\left(\mathrm{d}_{200}(\mathrm{Pt})=1,96 \AA\right)$ rotated $45^{\circ}$ with respect to the particle edges. Subsequent oxidation $\left(1 \mathrm{bar} \mathrm{O}_{2}\right.$, $673 \mathrm{~K}, 1 \mathrm{~h})$ and low-temperature reduction $\left(1 \mathrm{bar} \mathrm{H}_{2}, \mathrm{~T} \leq\right.$ $673 \mathrm{~K}, 1 \mathrm{~h})$ does not lead to significant changes, except for the appearance of higher-indexed facets, generally observed as particle ,rounding“ in low-resolution images [1].

Reduction at $\geq 773 \mathrm{~K}$ leads to a quite different picture. Fig. 2a shows Pt particles on silica after a reductive treatment at $873 \mathrm{~K}$. Most particles have changed shape and orientation. While one fraction has increased in size, obviously by coalescence, a considerable number of particles exhibit a characteristic cube or platelet shape with sharp edges. The corresponding SAED pattern (insert) still shows distinct, but broadened Pt spots, but also series of rings. Thus, some particles have changed their azimuthal orientation, but are still in [001] zone. Apart from (200) and (220), also (111) and (311) reflections belonging to a [110] zone can be detected,

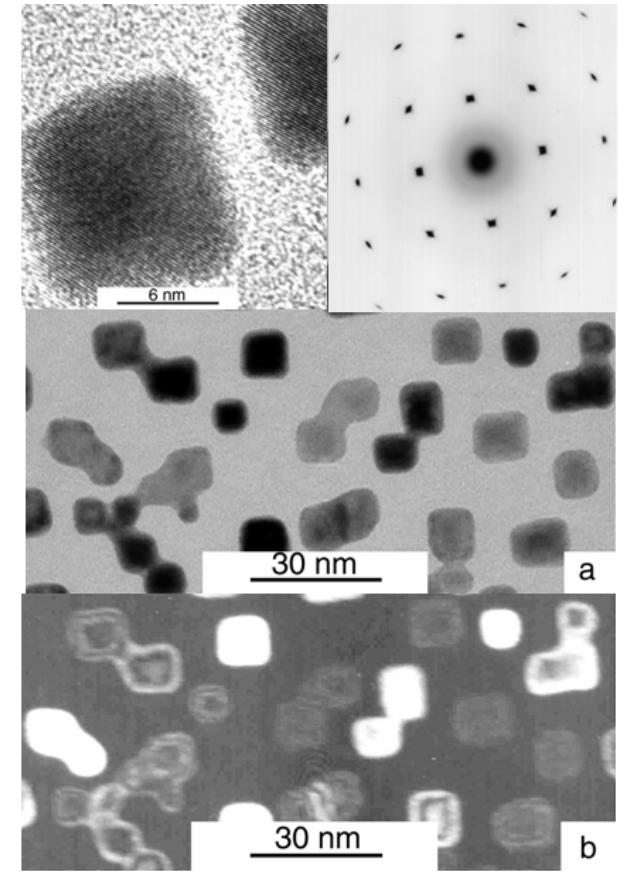

Fig. 1: As-grown Pt particles supported by $\mathrm{SiO}_{2}$ (a) brightfield, (b) weak-beam dark field image. Inserts: HREM image of an octahedral Pt particle and selected area diffraction pattern.

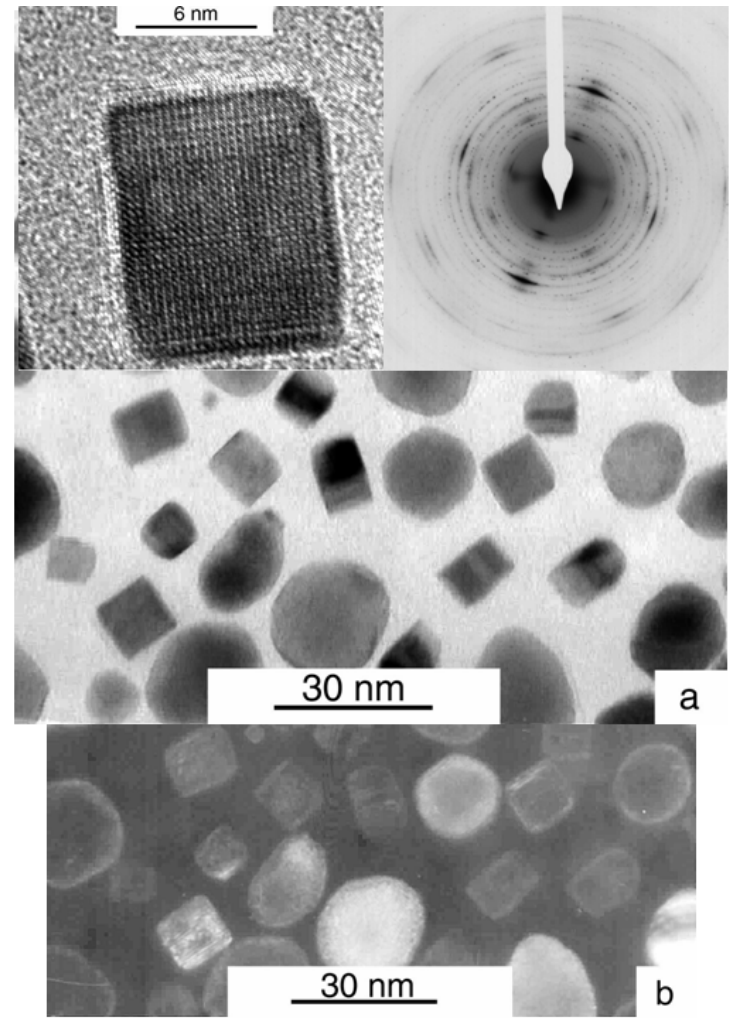

Fig. 2: Pt particles on silica after reduction in $\mathrm{H}_{2}$ at $873 \mathrm{~K}$ for 1h. (a) bright-field, (b) dark field. Left insert: HREM 
which suggests a change of base planes of some particles. Additional weaker spots coincide with forbidden (100) and image of a cube-shaped particle. Right insert: electron diffraction pattern.

(110) Pt reflections, but can be attributed to $\mathrm{Pt}_{3} \mathrm{Si}$ with a primitive cubic $\left(\mathrm{Cu}_{3} \mathrm{Au}\right)$ structure $(\mathrm{a}=3,89 \AA)$. (Table 1) [5]. Moreover, the high-resolution images of particles with sharp edges (insert) reveal periodicities parallel to these edges which may be regarded either as a doubling of the (200) distance of fcc Pt $\left(2 \times \mathrm{d}_{200}(\mathrm{Pt})=3,92 \AA\right)$, or as arising from $\mathrm{Pt}_{3} \mathrm{Si}(3,89 \AA)$. Further reflections in the diffraction pattern may arise from hexagonal low-temperature quartz ([6] and/or from other silicide modifications (see below) cf. Table1). In the corresponding dark-field images (Fig. 2b) no characteristic fringes due to thickness variations are detected, hence most particles have changed from truncated octahedra to cube or platelet like structures. This phase transformation is reversed upon heating in oxygen in $673 \mathrm{~K}$ for $1 \mathrm{~h}$. Subsequent reduction in hydrogen at $673-873 \mathrm{~K}$ reestablishes the previous state as documented by electron diffraction: Upon oxidising the "HTR" phase all reflections except those of the fcc Pt structure vanish, but they reappear after HTR. However, with increasing reduction temperature and time more "agglomerated" and rounded particles are observed and the diffraction pattern becomes more and more complex. A detailed analysis [7] indicates the formation of monoclinic $\mathrm{Pt}_{3} \mathrm{Si}$ (denoted by " $\mathrm{m}$ " in table 1 ) and of silicon richer structures like $\mathrm{Pt}_{12} \mathrm{Si}_{5}$. Analogous reduction experiments have been performed with a Pt/alumina thin film containing originally identical Pt particles (mean size $10 \mathrm{~nm}$, thickness of alumina $15 \mathrm{~nm}$ ). The as-deposited alumina is amorphous, but may crystallise in the electron beam and during oxidation and reduction. Fig. 3 shows the catalyst after reduction to $873 \mathrm{~K}$ together with a SAED pattern and

Table 1: Experimental interplanar distances $\mathrm{d}_{\mathrm{hkl}}[\AA]$ and possible correlation to $\mathrm{Pt}_{3} \mathrm{Si}$ (cubic), $\mathrm{Pt}_{3} \mathrm{Si}$ (monoclinic), $\mathrm{Pt}_{12} \mathrm{Si}_{5}$, and $\mathrm{Pt}_{3} \mathrm{Al}$.

\begin{tabular}{|c|c|c|c|}
\hline $\begin{array}{c}\text { Exp. distances } d_{h k 1} \\
\operatorname{Pt}_{\mathrm{x}} \mathrm{Si}_{\mathrm{y}}[\AA]\end{array}$ & Assignment & $\begin{array}{c}\text { Exp. distances d } d_{h k l} \\
\operatorname{Pt}_{x} A l_{y}[\AA]\end{array}$ & Assignment \\
\hline 3,91 & $\mathrm{Pt}_{3} \mathrm{Si}(\mathrm{c})(100)$ or $\mathrm{Pt}_{3} \mathrm{Si}(\mathrm{m})(002)$ & 3,92 & $\mathrm{Pt}_{3} \mathrm{Al}(100)$ \\
\hline 3,45 & $\gamma-\mathrm{SiO}_{2}(101)$ or $\mathrm{Pt}_{12} \mathrm{Si}_{5}(301)$ & & \\
\hline 3,00 & $\mathrm{Pt}_{12} \mathrm{Si}_{5}(420)$ & 2,95 & \\
\hline 2,76 & 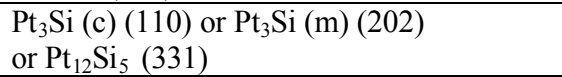 & 2,79 & $\mathrm{Pt}_{3} \mathrm{Al}(110)$ \\
\hline 2,69 & $\mathrm{Pt}_{3} \mathrm{Si}(\mathrm{m})(-202)$ & 2,61 & \\
\hline 2,46 & $\gamma-\mathrm{SiO}_{2}(110)$ & & \\
\hline 2,36 & $\mathrm{Pt}_{3} \mathrm{Si}(\mathrm{m})(113)$ or $\mathrm{Pt}_{12} \mathrm{Si}_{5}$ & 2,29 & $\mathrm{Pt}(111)$ or $\gamma-\mathrm{Al}_{2} \mathrm{O}_{3}$ \\
\hline 2,20 & $\mathrm{Pt}_{3} \mathrm{Si}(\mathrm{c})(111)$ or $\mathrm{Pt}_{3} \mathrm{Si}(\mathrm{m})(-222)$ & 2,19 & $\mathrm{Pt}_{3} \mathrm{Al}(111)$ \\
\hline 2,13 & $\mathrm{Pt}_{12} \mathrm{Si}_{5}(620)$ & & \\
\hline 1,96 & $\mathrm{Pt}(200)$ or $\mathrm{Pt}_{3} \mathrm{Si}(\mathrm{c})(200)$ & 1,98 & $\begin{array}{l}\mathrm{Pt}_{3} \mathrm{Al}(200) \text { or } \mathrm{Pt}(200) \text { or } \\
\gamma-\mathrm{Al}_{2} \mathrm{O}_{3} \\
\end{array}$ \\
\hline 1,81 & $\begin{array}{l}\mathrm{Pt}_{3} \mathrm{Si}(\mathrm{c})(210) \text { or } \mathrm{Pt}_{3} \mathrm{Si}(\mathrm{m})(313) \text { or } \mathrm{Pt}_{12} \mathrm{Si}_{5} \\
(003)\end{array}$ & 1,74 & $\mathrm{Pt}_{3} \mathrm{Al}(210)$ \\
\hline 1,58 & $\mathrm{Pt}_{3} \mathrm{Si}(\mathrm{c})(211)$ & 1,54 & $\mathrm{Pt}_{3} \mathrm{Al}(211)$ \\
\hline 1,38 & $\begin{array}{l}\mathrm{Pt}_{3} \mathrm{Si}(\mathrm{c})(220) \text { or } \mathrm{Pt}(220) \text { or } \\
\mathrm{Pt}_{3} \mathrm{Si}(\mathrm{m})(404)\end{array}$ & 1,41 & $\begin{array}{l}\mathrm{Pt}_{3} \mathrm{Al}(220) \text { or } \\
\mathrm{Pt}(220) \text { or } \gamma-\mathrm{Al}_{2} \mathrm{O}_{3}\end{array}$ \\
\hline
\end{tabular}

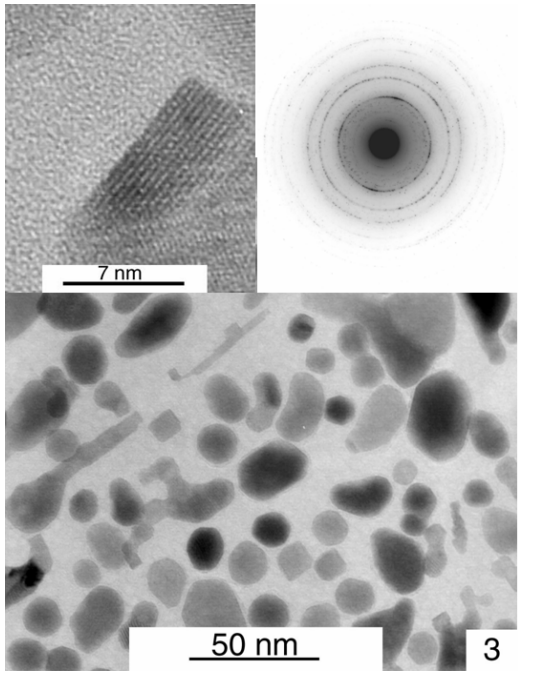

Fig. 3: Pt particles on alumina after reduction in $\mathrm{H}_{2}$ at $873 \mathrm{~K}$ for $1 \mathrm{~h}$. Left insert: HREM image of a cube-like particle. Right insert: electron diffraction pattern. the high-resolution image of a selected particle. Apart from larger (agglomerated) and "round" aggregates many particles have developed similar cube or platelet-like structures as on silica, again in contrast to the original octahedral shape. The electron diffraction pattern and the HREM image (inserts) reveal again a periodicity of $3,92 \pm 0,05 \AA$. Apart from ring reflections arising from $\gamma$-alumina many reflections are close to those measured on the silica-supported catalyst and indicate the presence of $\mathrm{Pt}_{3} \mathrm{Al}$, also of $\mathrm{Cu}_{3} \mathrm{Au}$

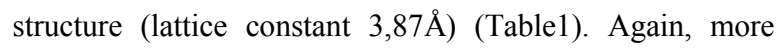
complex structures are formed upon reduction at higher temperature and for longer times. These are also more easily observed after adding metallic aluminium to the alumina support film before the reduction and must be attributed to more Al enriched alloy phases, particularly PtAl [8].

Quite analogous "primary" structures, i.e. cube and platelet shapes, were also observed upon reduction of the ceriasupported Pt nanocrystals between 773 and $973 \mathrm{~K}$. 
Again they are most likely attributed to $\mathrm{Pt}_{3} \mathrm{Ce}$, also with a $\mathrm{Cu}_{3} \mathrm{Au}$ lattice $(\mathrm{a}=4,16 \AA)$. Here also further reduction leads to different particle habits [9], but also to changes of composition and structure of the support, as will be discussed separately [10].

\section{Discussion and conclusions}

The discussion about structural changes of Pt particles upon high-temperature hydrogen reduction has been going on for some time. Cube-like structures with sharp edges have been already reported before high-resolution EM became available $[11,12]$, and were attributed to surface reconstruction under the influence of hydrogen, leading the system to minimum surface energy [13]. That alloy formation has to be taken into account was shown by Lamber et al. [5] who observed diffraction features compatible with $\mathrm{Pt}_{3} \mathrm{Si}$ after heating a Pt/silica model catalyst in hydrogen at $840 \mathrm{~K}$. Under the given experimental conditions alloy formation is thermodynamically feasible for all three described systems [14]. Density functional calculations of energies of formation and lattice parameters of some relevant $\mathrm{PtMe}$ and $\mathrm{Pt}_{3} \mathrm{Me}$ compounds (as summarized in Table 2) were performed by

Table 2: VASP-calculated formation energies $[\mathrm{eV}]$ of several relevant alloys

\begin{tabular}{|l|l|l|}
\hline Phase & $\mathbf{E}_{\mathbf{f}}[\mathbf{e V}]$ & $\mathbf{E}_{\mathbf{f}}$ per atom $[\mathbf{e V}]$ \\
\hline $\mathrm{Pt}_{3} \mathrm{Si}$ & $-1,201$ & $-0,300$ \\
\hline $\mathrm{PtSi}$ & $-1,278$ & $-0,639$ \\
\hline $\mathrm{Pt}_{3} \mathrm{Al}$ & $-2,754$ & $-0,689$ \\
\hline $\mathrm{PtAl}$ & $-2,109$ & $-1,055$ \\
\hline $\mathrm{Pt}_{3} \mathrm{Ce}$ & $-3,888$ & $-0,972$ \\
\hline
\end{tabular}

the ab-initio approach VASP [15], and confirm the high stability of the initially formed $\mathrm{Cu}_{3} \mathrm{Au}$ structures.

Hence, if we start from the pure oxide in intimate contact with the Pt metal particles, we may assume the formation of the $\mathrm{Pt}$ rich and stable $\mathrm{Pt}_{3} \mathrm{Me}$ phase as a first step. This may, however, be initiated by a reconstruction of the original octahedral particles into cubes under hydrogen, thereby facilitating the topotactic growth of the alloy in the proper orientation. The crystallographic alignment of the original particles provides the opportunity to monitor the reorientation process. In contrast to possible hydride intermediates the resulting alloys are kinetically stable under ambient conditions.

After reduction, EELS spectra of alumina covered Pt particles show a shift of the plasmon peak by about $2 \mathrm{eV}$ compared to the pure alumina support, which is also consistent with alloy formation. Conclusively, alloy formation, possibly preceded by surface reconstruction, is likely to occur in all three systems by topotactic growth of $\mathrm{Pt}_{3} \mathrm{Me}$ as a first step. Possible reasons for the absence of cube-like shapes, or of alloy formation, as sometimes stated under otherwise comparable experimental conditions [16], could be the absence of a preferred relationship between Pt and support, e.g. of topotactic nuclei or kinetic inhibition, e.g. less contact area between the support and particles grown on top of the support.

\section{Acknowledgement}

Part of this work was supported by the Austrian Science Fund (Projects S 8105 and S 8106).

\section{References}

[1] G. Rupprechter, K. Hayek, L. Rendon and M. José-Yacaman, Thin Solid Films 260 (1995) 148.

[2] K. Hayek, M. Fuchs, B. Klötzer, W. Reichl and G. Rupprechter, Top. Catal. 13 (2000) 55 .

[3] G. L. Haller, D. E. Resasco, Adv. Catal. 36 (1989) 173.

[4] G. J. den Otter and F. M. Dautzenberg, J. Catal. 53 (1978) 116.

[5] R. Lamber and N. Jaeger, J. Appl. Phys. 70 (1991) 457.

[6] Powder Diffraction File 1994, PDF 2 Database 1-44, International Center for Diffraction Data.

[7] D. Wang, S. Penner, G. Rupprechter, D.S. Su, K. Hayek and R. Schlögl, submitted to Mat. Chem. Phys.

[8] W. Bronger, P. Müller and K. Wrzesien, Z. Anorg. Allg. Chem. 623 (1997) 362.

[9] S. Bernal, J. J. Calvino, M. A. Cauqui, J. M. Gatica, C. Larese, J.A. Pérez-Omil and J. M. Pintado, Catal. Today 50 (1999) 175.

[10] S. Penner D. Wang, D. S. Su, G. Rupprechter, R. Schlögl and K. Hayek, submitted to Vacuum.

[11] T. Wang, C. Lee and L.D. Schmidt, Surf. Sci. 163 (1985) 181.

[12] W. Romanowski and R. Lamber, Thin Solid Films 127 (1985) 139.

[13] A.-C. Shi and R.I. Masel, J. Catal. 120 (1989) 421.

[14] Landolt-Börnstein New Series IV/5a, IV/5c and IV/5I.

[15] G. Kresse and J. Hafner, Phys. Rev. B 47 (1993) RC558

[16] A.S. Ramachandran, S.L. Anderson and A.K. Datye, Ultramicroscopy 51 (1993) 282. 